\title{
An updated systematic review and meta-analysis on the social determinants of diabetes and related risk factors in the Caribbean
}

\author{
Leonor Guariguata, ${ }^{1}$ Catherine Brown, ${ }^{1}$ Natasha Sobers, ${ }^{2}$ Ian Hambleton, ${ }^{1}$ \\ T. Alafia Samuels, ${ }^{1}$ and Nigel Unwin ${ }^{3}$
}

Suggested citation

Guariguata L, Brown C, Sobers N, Hambleton I, Samuels TA, Unwin N. An updated systematic review and meta-analysis on the social determinants of diabetes and related risk factors in the Caribbean. Rev Panam Salud Publica. 2018;42:e171. https://doi.org/10.26633/RPSP.2018.171

ABSTRACT Objectives. To conduct an analysis of the most recent data on diabetes and its risk factors by gender and other social determinants of health to understand why its prevalence is higher among women than men in the Caribbean; to inform policy agenda-setting for diabetes prevention and control in the Caribbean; and to identify gaps in the evidence that require further research.

Methods. A previous systematic review of the literature describing studies conducted in the Caribbean that presented the distribution of diabetes, its outcomes, and risk factors, by one or more social determinants, was updated to include sources from 1 January 2007 - 31 December 2016. Surveys by the World Health Organization (WHO) were also included. Where data were sufficient, meta-analyses were undertaken.

Results. A total of 8326 manuscripts were identified. Of those, 282 were selected for full text review, and 114, for abstraction. In all, 36 papers, including WHO-related surveys, had sufficient information for meta-analysis. More women compared to men were obese (OR: $2.1 ; 95 \% C I=1.65$ -2.69), physically inactive (OR: $2.18 ; 95 \% C I=1.75-2.72)$, and had diabetes (OR: $1.48 ; 95 \% C I=$ 1.25 - 1.76). More men smoked (OR: $4.27 ; 95 \% C I=3.18-5.74)$ and had inadequate fruit and vegetable intake (OR: $1.37 ; 95 \% \mathrm{CI}=1.21-1.57$ )

Conclusion. Thirty-six papers were added to the previously conducted systematic review; of those, 13 were added to the meta-analysis. Diabetes and its risk factors (primarily obesity and physical inactivity) continue to disproportionately affect women in the Caribbean. Smoking interventions should be targeted at men in this geographic area.

Keywords Diabetes mellitus; noncommunicable diseases; gender and health; obesity; risk factors; Caribbean region.

George Alleyne Chronic Disease Research Centre, Caribbean Institute for Health Research, The University of the West Indies, Bridgetown, Barbados. Send correspondence to Leonor Guariguata, leonor.guariguata@gmail.com

2 Faculty of Medical Sciences, The University of the West Indies, Bridgetown, Barbados.

3 Medical Research Council Epidemiology Unit, University of Cambridge, Cambridge, United Kingdom.
Diabetes is a major cause of death and disability around the world and is projected to increase in the coming decades (1). Type 2 diabetes represents $80 \%-90 \%$ of the total diabetes burden, with the main proximal risk factors being overweight and obesity, physical inactivity, unhealthy diet, and tobacco smoking (1). The prevalence of type 2 diabetes and its risk factors are strongly associated with underlying social and economic factors (2), with poorer, less educated people often being disproportionally affected. The World Health Organization 
(WHO) has prioritized examining the social determinants of health in order to guide preventive interventions for several diseases, including diabetes and cardiovascular disease (3).

It has been reported that in the Caribbean, women may be at greater odds for diabetes (OR: 1.65; 95\%CI = $1.43-1.91)$ and obesity (OR: 3.10; 95\%CI = $2.43-$ 3.94) than men (4). Sobers-Grannum and colleagues examined the effects of gender on diabetes, its risk factors, and outcomes in the Caribbean in a systematic review published in 2015 (4). In addition to gender, the review sought to describe data on a range of social determinants of health, but evidence was scant, making it impossible to provide even a narrative review of the relationship of outcomes to other social determinants.

Guided by the analytical framework recommended by the WHO Commission on the Social Determinants of Health (3), the present study updates the previous systematic review (4) with new data, including new information on physical activity, a wider range of social determinants, and sources from the grey literature. The objective of this review was to inform policy agenda-setting for diabetes prevention and control in the Caribbean, and to identify gaps in the evidence where further research is needed.

\section{MATERIALS AND METHODS}

This was a systematic review of diabetes distribution, risk factors, and outcomes, by social determinants of health, in the Caribbean. The study protocol for this review followed that of SobersGrannum and colleagues (4) and added newer data collected from NCD survey reports available on the websites of the Pan American Health Organization (PAHO) and WHO. In short, using the same search strategies as the original (4), this review included data for three additional years (2014 - 2016), extending the collection from 1 January 2007 - 31 December 2016. A search was conducted for studies in the Caribbean-its countries and territories as defined by Samuels and colleagues (5) - that reported on diabetes distribution, risk factors, and outcomes, by one or more social determinant(s). Guided by the Progress-plus checklist (6), the social determinants examined were: gender; marital status; income; housing; urban/rural location; education; ethnicity; and owning household assets.

Diabetes outcomes and risk factors were considered among both the general population and those with diabetes. For the general population, the review looked at: obesity, including measures of body mass index (BMI), waist circumference (WC), and abdominal obesity; physical inactivity; tobacco use; measures of diet quality, e.g., consumption of fruits and vegetables, diet quality scores, etc.; and type 1 and type 2 diabetes prevalence and incidence. Among those with diabetes, the review considered: control measures, including glucose, glycated hemoglobin, blood pressure, and lipids; measures of incidence or prevalence of retinopathy, nephropathy, neuropathy, diabetic foot, and lower extremity amputation; and mortality.

Search criteria were deliberately kept broad so as to capture any relationship related to diabetes and one of the social determinants. Studies included had:

- Caribbean study population

- Adult participants ( $\geq 18$ years of age) when considering diabetes and its outcomes, or participants $\geq 12$ years when considering risk factors

- Outcomes stratified by at least one of the social determinants

- Quantitative study design (observational/intervention)

- Sample size $\geq 50$ people

Excluded studies had:

- Diaspora study population or other non-Caribbean

- Narrative review design, commentary, case series, qualitative study, or single case report

A systematic search was conducted of PubMed Central (U.S. National Library of Medicine, Bethesda, Maryland, United States); EMBASE (Excerpta Medica Database, Elsevier, Amsterdam, the Netherlands); the Virtual Health Library, including LILACS (Latin American and Caribbean Center on Health Sciences Information, PAHO/WHO, São Paolo, Brazil; BIREME); MedCarib (Health sciences data from the English speaking Caribbean; BIREME); and IBECS (Biographic Index on Health Sciences; BIREME). Reports from the WHO STEP-wise approach to noncommunicable disease risk factor surveillance surveys (STEPS; 7) and other nationally representative NCD reports were identified from PAHO (8) and WHO (9) websites. Studies were included if the complete text was available; if not, they were excluded. There were no limits regarding the language of publication.

Bibliographic information for each study was entered into the Rayyan online data system (Qatar Computing Research Institute, Doha, Qatar; 10). Titles and abstracts were independently reviewed by two reviewers (LG and CB); conflicts were resolved by a third reviewer (NS). The full text of all retained articles was sought, and where available, was independently abstracted by two reviewers (LG and CB); again, any differences were resolved in discussion with a third reviewer (NS). Analysis was conducted at the relationship level between individual social determinants and outcomes, since several relationships could exist within a single study.

A form for data abstraction was designed using OpenOffice ${ }^{\mathrm{TM}}$ Base (Oracle Corporation, Santa Clara, California, United States). The form was guided by the STROBE statement (11) for reporting observational epidemiology and by the PRISMA statement on systematic reviews concerning health equality (12). The PRISMA statement was also consulted for reporting results (13).

Risk of bias was assessed using criteria applied by Brown and colleagues (14) for each relationship and classified as follows:

1. Low risk of bias (all criteria are met)—response rate $>75 \%$, missing data $<10 \%$, full description of sampling strategy, adjustment of measures by age and other potential confounders (such as sex or ethnicity), as appropriate, and objective measurement of disease measures;

2. Medium risk of bias (one or more criterion)-response rate $50 \%-75 \%$, missing data $10 \%-15 \%$, adjustment of measures by age and other potential confounders (such as sex or ethnicity), as appropriate, and subjective measurement of disease measures;

3. High risk of bias (one or more criterion)-response rate $\leq 50 \%$, missing data $>15 \%$, inappropriate adjustment for confounders (i.e., missing important adjustment or no adjustment), poor sampling strategy, inappropriate assessment of the disease measure;

4. Unclear-not enough information to make an assessment. 
Only population-based, cross-sectional studies that measured the outcomes as dichotomous variables were included for meta-analysis. Meta-analyses were conducted and random effects models were fitted, including I-squared values for obesity and gender (heterogeneity, $\mathrm{I}^{2}=96 \%$ ), physical inactivity and gender $\left(\mathrm{I}^{2}=94.4 \%\right)$, insufficient fruit and vegetable intake and gender $\left(\mathrm{I}^{2}=94.4 \%\right)$, smoking/tobacco use and gender $\left(\mathrm{I}^{2}=\right.$ $94.7 \%$ ), and diabetes prevalence and gender $\left(\mathrm{I}^{2}=88.1 \%\right)$. Other social determinants were too heterogeneously defined to allow for meta-analysis; these were described narratively.

Only subjectively measured physical inactivity estimates were available.

FIGURE 1. Flowchart of the selection process highlighting the number of studies excluded and included in a study of diabetes and its risk factors in the Caribbean

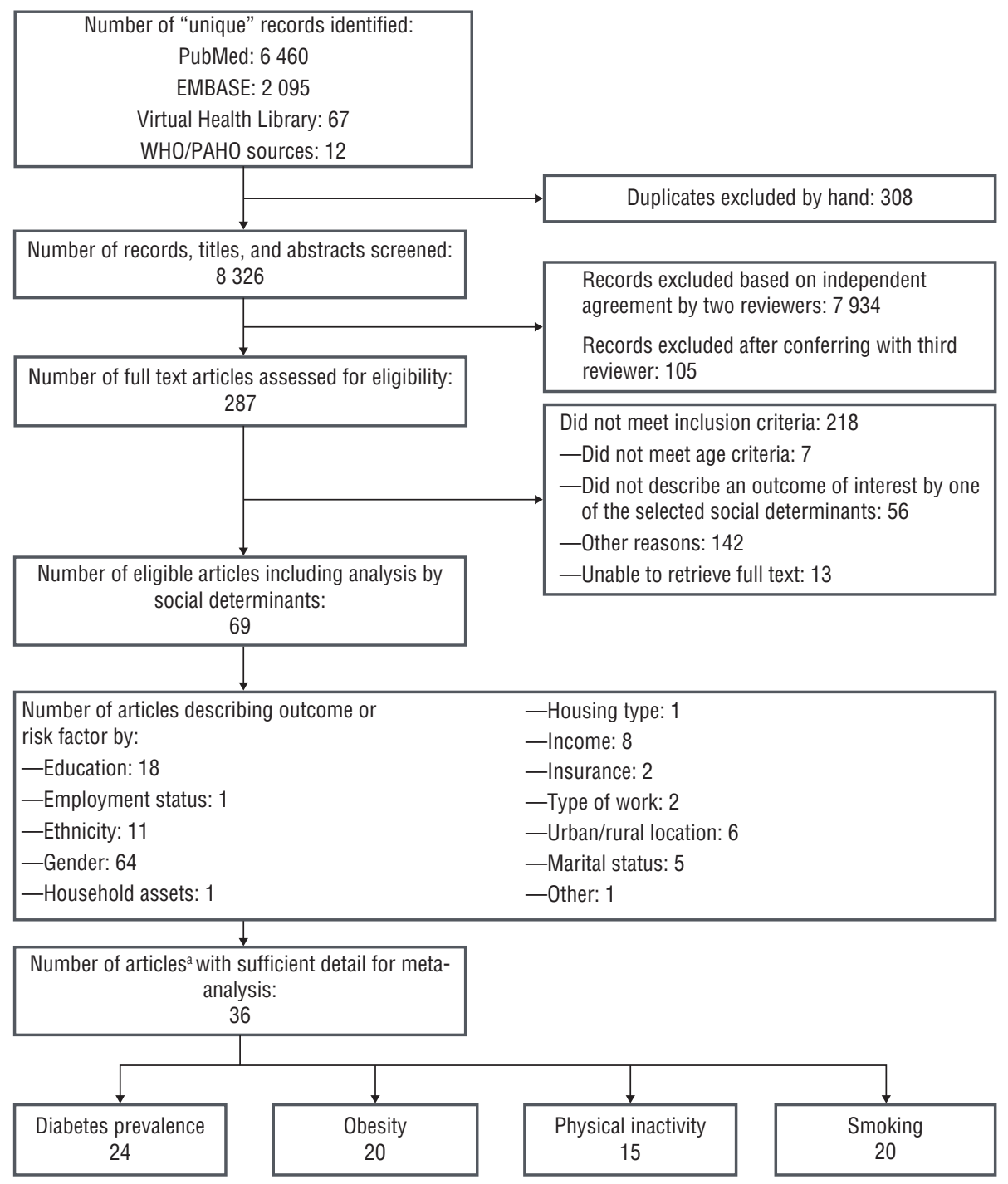

Source: Prepared by the authors from the study data.

a The numbers below reflect the number of datapoints or relationships available for meta-analysis. Some articles presented data for more than one country, and therefore, yielded multiple points.
Physical inactivity was defined dichotomously where subjects reported either no physical activity or physical activity below WHO-recommended levels (15).

\section{RESULTS}

The selection process is summarized in Figure 1. The 69 studies and reports, including nine $\mathrm{PAHO}$ and $\mathrm{WHO}$ sources with full reports available, yielded 374 relationships with the following social determinants: education $(n=33)$, employment $(n=14)$, ethnicity $(n=26)$, gender $(n=267)$, household assets $(n=1)$, housing type $(n=3)$, income $(n=10)$, insurance status $(n=4)$, urban/rural setting $(n=9)$, marital status $(n=7)$, and one classified as "other" (a composite definition of socioeconomic status used in that paper). The relationships presented data on the following measures: abdominal obesity ( $n$ $=48)$, aspects of diet $(n=31)$, blood pressure control $(n=6)$, diabetes incidence $(n=1)$, diabetes mortality $(n=3)$, diabetes prevalence $(n=71)$, diabetic retinopathy $(n=1)$, obesity $(n=80)$, pre-diabetes/hyperglycemia $(n=15)$, physical inactivity $(n=78)$, and smoking and tobacco use $(n=41)$. It was possible to have more than one paper published for a study. Measures were included in the narrative review when at least four relationships from multiple studies were available. A full matrix of relationships of outcomes by social determinants is available in Table 1. Overall relationship quality from risk of bias was as follows: high risk $(n=98)$, medium risk $(n=127)$, low risk $(n=68)$, and unclear $(n=81)$.

\section{Measures of obesity}

No significant difference in abdominal obesity (defined as elevated waist circumference) by ethnicity was found in adolescents in Jamaica (black versus non -black [reference]; 16) or Guadeloupe (17). In Suriname $(18,19)$, rates of abdominal obesity were highest among Amerindian indigenous populations $(71.6 \%, 95 \% \mathrm{CI}=62.5-79.8$; Creole $46.5 \%, 95 \% \mathrm{CI}=40.9-52.0$; Hindustani $65.5 \%, 95 \% \mathrm{CI}=62.3-68.6$; Javanese $52.3 \%, 95 \% \mathrm{CI}=47.4-57.1$; Maroon $52.2 \%$; $95 \% \mathrm{CI}=47.4-57.1$; Mixed 60.1\%; $95 \% \mathrm{CI}=54.9-65.0)$. In addition, obesity measured by BMI (both as a continuous variable and as a prevalence $\geq 30 \mathrm{~kg} / \mathrm{m}^{2}$ ) was described by ethnicity in 9 relationships across 7 studies: in Jamaica (16), Guadeloupe $(17,20)$, Suriname $(18,19)$, Trinidad and Tobago (21), and Barbados and Cuba (22). Studies found no significant differences in rates of obesity among black Jamaican adolescents (odds ratio [OR]: $1.03 ; 95 \% \mathrm{CI}=0.55-1.93$ ), or among black adults in Barbados and Cuba combined (OR:1.33; 95\%CI = $0.97-1.81)$ when compared to "white" (term used in the sources) subjects $(16,22)$. In Suriname $(18,19)$, mean BMI was highest among Amerindian indigenous populations (BMI: 28.6, standard deviation [SD]: 5.6), Creoles (BMI: 27.1 , SD 6.1), Hindustani 
TABLE 1. Number of relationships found, by social determinant and outcome, in a study of the social determinants of diabetes and its risk factors in the Caribbean

\begin{tabular}{|c|c|c|c|c|c|c|c|c|c|c|c|}
\hline Risk factors and outcomes & Education & Employment & Ethnicity & Gender & $\begin{array}{l}\text { Household } \\
\text { assets }\end{array}$ & $\begin{array}{l}\text { Housing } \\
\text { type }\end{array}$ & Income & $\begin{array}{c}\text { Health } \\
\text { insurance }\end{array}$ & $\begin{array}{l}\text { Urban/Rural } \\
\text { location }\end{array}$ & $\begin{array}{l}\text { Marital } \\
\text { status }\end{array}$ & Total \\
\hline Aspect of diet & 6 & 2 & 1 & 18 & 0 & 0 & 1 & 1 & 0 & 2 & 31 \\
\hline Diabetes prevalence & 10 & 3 & 5 & 40 & 0 & 1 & 0 & 1 & 5 & 2 & 67 \\
\hline Diabetic retinopathy & 0 & 0 & 0 & 1 & 0 & 0 & 1 & 0 & 0 & 0 & 2 \\
\hline Hyperglycemia & 1 & 0 & 1 & 9 & 0 & 0 & 0 & 2 & 1 & 0 & 14 \\
\hline Diabetes mortality & 0 & 0 & 0 & 3 & 0 & 0 & 3 & 0 & 0 & 0 & 6 \\
\hline Obesity & 6 & 2 & 4 & 62 & 0 & 0 & 2 & 0 & 1 & 0 & 77 \\
\hline Physical activity & 4 & 2 & 5 & 63 & 0 & 0 & 0 & 0 & 2 & 0 & 76 \\
\hline Smoking/tobacco use & 4 & 4 & 5 & 26 & 0 & 1 & 0 & 0 & 0 & 2 & 42 \\
\hline Total & 33 & 14 & 26 & 267 & 1 & 3 & 10 & 4 & 9 & 7 & 374 \\
\hline
\end{tabular}

Source: Prepared by the authors from study data.

(BMI: 27, SD 5.6), Javanese (BMI: 27.4; SD 5.5), Maroon (BMI: 27.3, SD 6.2), and Mixed (BMI: 27.4, SD 6.1), consistent with findings from the same study on elevated waist circumference. The study of Trinidad and Tobago did not provide details on confidence intervals or $P$ values so it was not clear whether or not there were significant differences between ethnicities regarding obesity (21). In Guadeloupe, no differences by ethnicity were found for mean BMI.

Six relationships across five studies described obesity by level of education. No significant differences in obesity by education were found among adults in three studies in Barbados and Cuba (22) that used data from the Barbados Eye study (23); neither were differences found in the study of Puerto Rico (24). A nationally representative study from Barbados (25) showed differences in obesity by education level with the most obese being those with a secondary education $(37.8 \%, 95 \% \mathrm{CI}=32.4-43.6)$, over those with the least education $(28.6 \%$, $95 \% \mathrm{CI}=23.1-34.8)$ and those with a university degree or higher (37.1\%, $95 \% \mathrm{CI}=25.7$ - 38.5); however, these differences were not significant. The studies from Barbados used different sampling methods and were conducted almost 20 years apart. Finally, a study among youth in Puerto Rico evaluated relationships between parental education and obesity, but found no significant relationship (26), and another in the Bahamas did not provide a clear description of educational levels (27).

Of 34 relationships assessing obesity (BMI) and 14 assessing elevated WC by

FIGURE 2a. Forest plot of odds of obesity by gender, women versus men (reference), in a study of the social determinants of diabetes and its risk factors in the Caribbean

(A) Forest plot of odds of obesity by gender, women v men(ref)

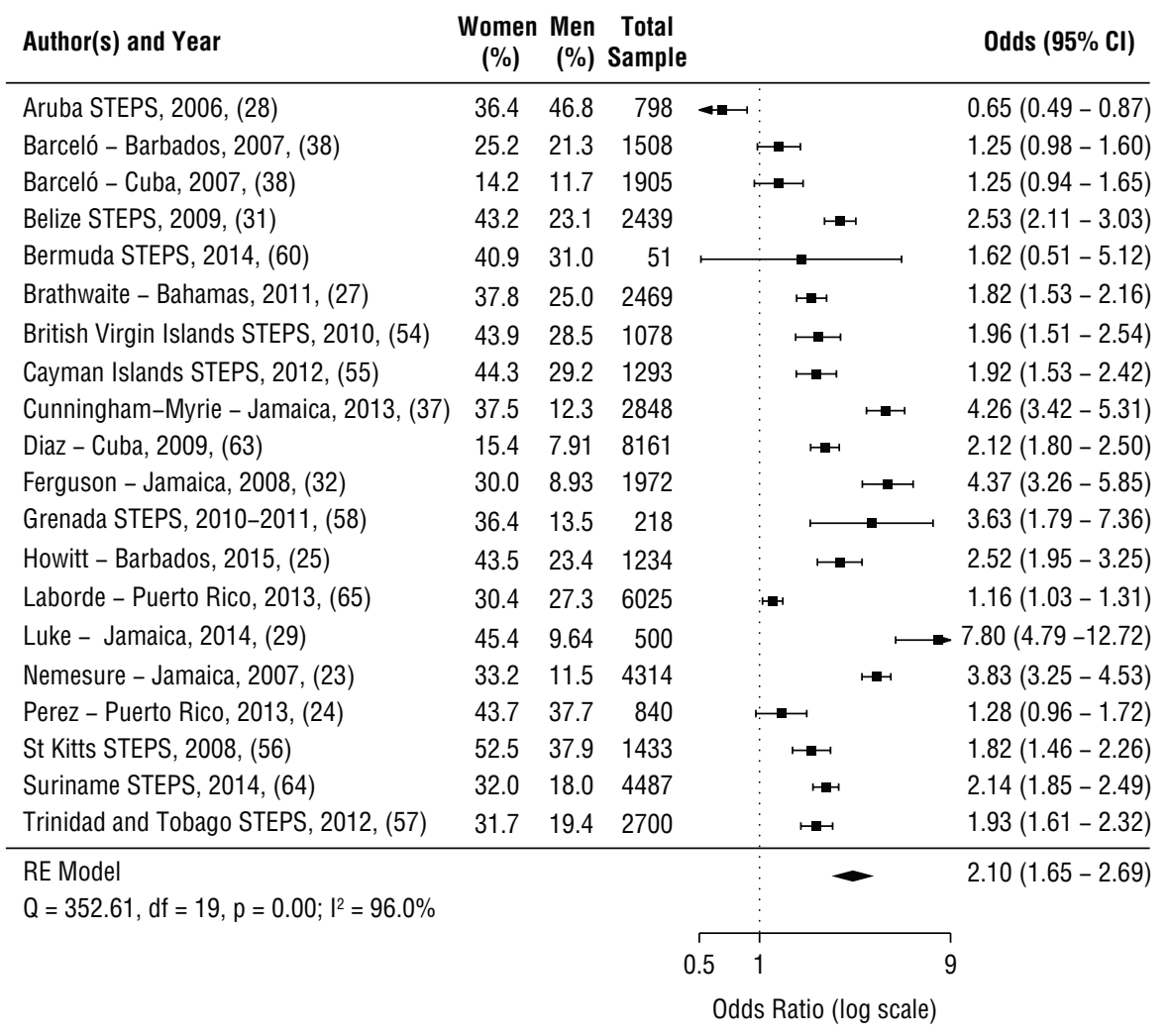

Source: Prepared by the authors using already published, publicly available data including tables and data presented in published papers and available on the PAHO (www.paho.org) and WHO (www.who.int) websites.

gender, only one study found more obesity in men than women (28). Meta-analysis of obesity prevalence by gender is presented in Figure 2a. Obesity prevalence was reported by 27 data sources; of those, 7 were excluded due to duplicate data, leaving a total of 20 relationships.
Overall, women in the Caribbean have $2.1(95 \% \mathrm{CI}=1.65-2.69)$ higher odds of obesity than men, and as high as 7.8 $(95 \% \mathrm{CI}=4.79-12.72)$ in a Jamaican sample (29). The only study reporting a higher odds in men than women was the Aruba STEPS survey (28). 
FIGURE 2b. Forest plot of odds of smoking by gender, women versus men (reference), in a study of the social determinants of diabetes and its risk factors in the Caribbean

(B) Forest plot of odds of smoking by gender, men v women(ref)

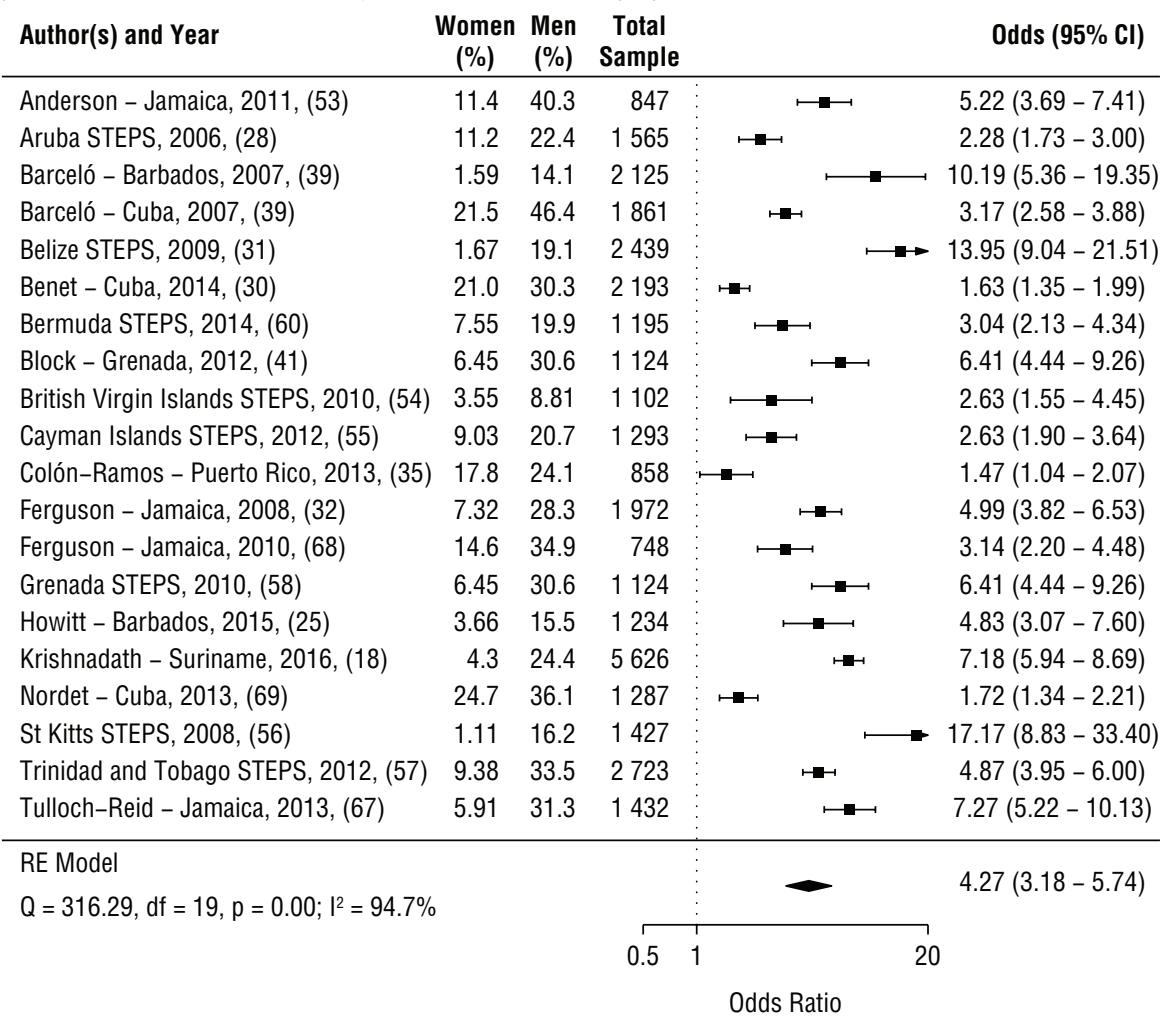

Source: Prepared by the authors using already published, publicly available data including tables and data presented in published papers and available on the PAHO (www.paho.org) and WHO (www.who.int) websites.

\section{Smoking and tobacco use}

No study found a higher prevalence of smoking in women than men. In 19 of 26 relationships, the smoking rate for women was $<10 \%$ compared to $>15 \%$ $34 \%$ for men. Two studies $(25,30)$ found decreasing prevalence of smoking or tobacco use with more years of education, although one survey in Belize did not find a clear pattern (31). In a meta-analysis of smoking and tobacco use by gender (Figure 2b), men had substantially higher odds of smoking (OR: 4.27; $95 \% \mathrm{CI}$ $=3.18-5.74)$ than women.

\section{Physical inactivity}

Across all studies, women were less physically active than men. Nationally representative population-based surveys in Jamaica (male 16.0\%; female 43.0; $P<$ $0.001 ; 32$ ), Suriname (recommended physical activity prevalence ratio: male [ref], female 0.78 [0.74-0.84] adjusted for age, ethnicity, area; 33), and Barbados (inactivity prevalence ratio: male versus female [ref] 0.47 [0.39 - 0.57] age adjusted; 25) all showed a significantly higher rate of physical inactivity in women compared to men. There was no consistent pattern between physical inactivity and years of education, although this was only assessed by four relationships across two studies. Physical inactivity and ethnicity were described in 5 relationships across 4 studies, but a variety of definitions for physical inactivity and classifications for ethnicity made it difficult to describe trends.

Meta-analysis of physical inactivity and gender (Figure 3a) yielded an odds ratio of $2.18(95 \% \mathrm{CI}=1.75-2.72)$ higher in women than men, and ranged from $1.36(95 \% \mathrm{CI}=1.11-1.66)$ in Aruba to 4.77 $(95 \% \mathrm{CI}=3.72-6.11)$ in Barbados.

\section{Aspects of diet}

Eighteen relationships evaluated an aspect of diet, by gender, with fruit and vegetable intake as the most commonly measured indicator. Other measures included subjective diet quality, fast food consumption, and fat intake.

Prevalence of insufficient intake of fruit and vegetables $(<5$ servings per day) were consistently $>80 \%$ for both genders across all studies. Intake tended to be lower in those with fewer years of education, but only 4 studies evaluated this relationship (25, $34-36)$. Meta-analysis (Figure $3 b$ ) showed higher odds of insufficient fruit and vegetable intake among men than women (OR: 1.37, $95 \% \mathrm{CI}=1.21-1.57)$, although absolute rates of insufficient intake were high across both genders.

\section{Diabetes prevalence}

Diabetes prevalence was significantly higher in people with less education in two studies in Jamaica (objectively measured prevalence: $<$ high school education, $14.3 \%, 95 \% \mathrm{CI}=12.2-16.8$; $\geq$ high school education, $4.9 \%, 95 \% \mathrm{CI}=3.9-6.1$, $P<0.001 ; 37)$ and in Trinidad and Tobago (self-reported prevalence: primary education, $24.8 \%, n=2$ 267; secondary education $10 \%, n=427$; university education $7.3 \%, n=8 ; P=0.000 ; 38)$. No significant differences by education were found in Barbados $(25,39)$ or Belize $(31)$, although trends were in the same direction. Only one study from Puerto Rico showed a trend of increased diabetes prevalence with more years of education (objectively measured prevalence: no formal education $6.6 \%$; grades $1-8,11.4 \%$; $\geq$ high school education, $11.9 \% ; P=0.013 ; 40$ ).

No significant differences were found regarding urban versus rural location and diabetes prevalence in 3 of 5 relationships in Belize (31) and Jamaica (32, 37). Only one study in Puerto Rico showed a significantly higher prevalence of diabetes in urban areas, but it was not age-adjusted (40).

In meta-analysis, diabetes prevalence was higher for women than men in both objective (OR: 1.35, 95\%CI = $1.03-1.76$ ) and subjective (OR:1.62, 95\%CI = 1.33 1.97) measurements (Figure 4).

\section{Diabetes control and complications}

Women with diabetes reported a higher prevalence of diagnosed high blood pressure than men in Barbados (women, 53.6\%; men, 37.9\%; $P<0.001$ ), Cuba (women, $49.8 \%$; men, $35.8 \%$; 
FIGURE 3a. Forest plot of odds of physical activity by gender, women versus men (reference), in a study of the social determinants of diabetes and its risk factors in the Caribbean

(A) Forest plot of odds of physical inactivity by gender, women v men(ref)

\begin{tabular}{|c|c|c|c|c|c|}
\hline Author(s) and Year & $\begin{array}{c}\text { Women } \\
(\%)\end{array}$ & $\begin{array}{l}\text { Men } \\
(\%)\end{array}$ & $\begin{array}{c}\text { Total } \\
\text { Sample }\end{array}$ & & Odds (95\% Cl) \\
\hline Aruba STEPS, 2006, (28) & 49.2 & 41.7 & 1539 & $\vdots-1$ & $1.36(1.11-1.66)$ \\
\hline Baldew - Suriname, 2015, (33) & 51.0 & 37.6 & 4487 & 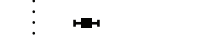 & $1.73(1.53-1.95)$ \\
\hline Bermuda STEPS, 2014, (60) & 33.6 & 20.3 & 1195 & $\mapsto$ & $1.99(1.53-2.59)$ \\
\hline British Virgin Islands STEPS, 2010, (54) & 42.5 & 23.5 & 1065 & $\longmapsto$ & $2.40(1.83-3.14)$ \\
\hline Cayman Islands STEPS, 2012, (55) & 44.3 & 24.0 & 1293 & $\mapsto$ & $2.51(1.97-3.19)$ \\
\hline Colon-Ramos - Puerto Rico, 2013, (35) & 39.4 & 37.3 & 858 & 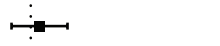 & $1.09(0.82-1.46)$ \\
\hline Cunningham-Myrie - Jamaica, 2013, (37) & 42.7 & 15.7 & 2848 & $\rightarrow$ & $4.00(3.27-4.89)$ \\
\hline Ferguson - Jamaica, 2008, (32) & 50.9 & 21.3 & 1972 & $\mapsto$ & $3.82(3.08-4.74)$ \\
\hline Grenada STEPS, 2011, (58) & 41.1 & 26.7 & 101 & & $1.92(0.82-4.48)$ \\
\hline Howitt - Barbados, 2015, (25) & 67.1 & 30.0 & 1234 & $\mapsto$ & $4.77(3.72-6.11)$ \\
\hline Krishnadath - Suriname, 2016, (18) & 43.1 & 28.7 & 4854 & 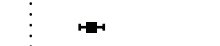 & $1.88(1.66-2.13)$ \\
\hline Rodrigues Barbosa - Barbados, 2010, (66) & 60.1 & 53.3 & 1508 & $\mapsto$ & $1.32(1.07-1.63)$ \\
\hline St Kitts STEPS, 2008, (56) & 48.1 & 28.3 & 317 & & $2.38(1.49-3.79)$ \\
\hline Suriname STEPS, 2014, (64) & 51.0 & 37.6 & 4487 & 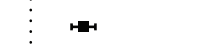 & $1.73(1.53-1.95)$ \\
\hline Trinidad and Tobago STEPS, 2012, (57) & 57.0 & 33.0 & 2632 & $\rightarrow$ & $2.69(2.29-3.17)$ \\
\hline \multirow[t]{3}{*}{$\begin{array}{l}\text { RE Model } \\
Q=201.11, d f=14, p=0.00 ; l^{2}=94.4 \%\end{array}$} & & & & & $2.18(1.75-2.72)$ \\
\hline & & & 0.5 & 1 & \\
\hline & & & & Odds & \\
\hline
\end{tabular}

Source: Prepared by the authors using already published, publicly available data including tables and data presented in published papers and available on the PAHO (www.paho.org) and WHO (www.who.int) websites.

FIGURE 3b. Forest plot of odds of insufficient fruit and vegetable intake by gender, women versus men (reference), in a study of the social determinants of diabetes and its risk factors in the Caribbean

(B) Forest plot of odds of insufficient fruit and vegetable intake by gender, women(ref) v men

\begin{tabular}{|c|c|c|c|c|c|}
\hline Author(s) and Year & $\begin{array}{c}\text { Women } \\
(\%)\end{array}$ & $\begin{array}{l}\text { Men } \\
(\%)\end{array}$ & $\begin{array}{c}\text { Total } \\
\text { Sample }\end{array}$ & & Odds (95\% CI) \\
\hline Aruba STEPS, 2006, (28) & 96.9 & 98.5 & 1555 & 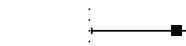 & $2.12(1.02-4.39)$ \\
\hline BVI STEPS, 2010, (54) & 92.4 & 92.3 & 1101 & $\longrightarrow$ & $0.98(0.62-1.53)$ \\
\hline Cayman STEPS, 2012, (55) & 81.8 & 85.5 & 1293 & 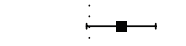 & $1.32(0.98-1.77)$ \\
\hline Colon Lopez - Puerto Rico, 2013, (34) & 93.8 & 91.9 & 593 & $\hookrightarrow \vdots$ & $0.75(0.38-1.47)$ \\
\hline Grenada STEPS, 2010-2011, (58) & 71.9 & 78.7 & 1129 & $\longrightarrow$ & $1.44(1.09-1.91)$ \\
\hline Howitt - Barbados, 2015, (25) & 88.5 & 91.7 & 1234 & $\longrightarrow$ & $1.44(0.97-2.14)$ \\
\hline St Kitts STEPS, 2008, (56) & 97.0 & 97.5 & 1416 & - & $1.22(0.63-2.39)$ \\
\hline Trinidad STEPS, 2012, (57) & 89.3 & 92.8 & 2666 & $\longmapsto$ & $1.54(1.17-2.04)$ \\
\hline
\end{tabular}

RE Model

$Q=201.11, d f=14, p=0.00 ; I^{2}=94.4 \%$

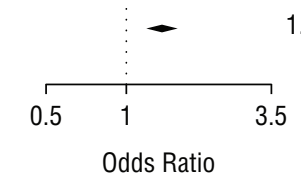

Source: Prepared by the authors using already published, publicly available data including tables and data presented in published papers and available on the PAHO (www.paho.org) and WHO (www.who.int) websites.

$P=0.00$ ), and Grenada (women, 35\%; men, $21 \%$; $P<0.001)(22,41)$.

For blood glucose control, no significant difference by gender was found in Jamaica (32) or in Trinidad (42). Only one

\section{Mortality}

There were no studies that described mortality in populations or groups of people with diabetes by social determinants, and only one that found mortality in the general population (44); however, it did not meet the inclusion criteria.

\section{DISCUSSION}

This update of the systematic review by Sobers-Grannum and colleagues (4) on diabetes distribution, risk factors, and outcomes in the Caribbean was designed to incorporate new evidence from peer-reviewed articles published in 1 January 2014 - 31 December 2016 and a broader scope that includes social determinants beyond gender. Moreover, this review features WHO STEP surveys that are largely unpublished in peer reviewed journals. The new data confirm findings from the original review indicating that women bear a higher burden of diabetes in the Caribbean. This higher burden can be partly attributed to a greater risk of obesity via lower levels of physical activity (and likely, dietary intake). This distribution is highly unusual in the global profile of diabetes (45) where most regions show men as having a higher prevalence than women. Adding data from WHO and PAHO surveys underscores this gender inequality and adds enough data to analyze physical inactivity and insufficient fruit and vegetable intake.

Both insufficient fruit and vegetable intake and tobacco use and smoking were more common in men than in women. Rates of insufficient fruit and vegetable intake were high across both genders, however, so measures should be taken at a population level to improve consumption. While smoking increases the risk of diabetes by as much as 50\% (46), smoking rates in the Caribbean for men are typically around $20 \%$, and for women, around $6 \%$. These rates are low compared to other parts of the world. However, they are still a contributing factor to diabetes prevalence, particularly among men (47).

With respect to control and complications of diabetes, although the data were not conclusive, they were suggestive of poorer outcomes for women. Whether this reflects an overall increased burden for women or differences in health-seeking behavior or access to care remains to be evaluated. 
FIGURE 4. Forest plot of odds of diabetes, by gender, women versus men (reference), in a study of the social determinants of diabetes and its risk factors in the Caribbean

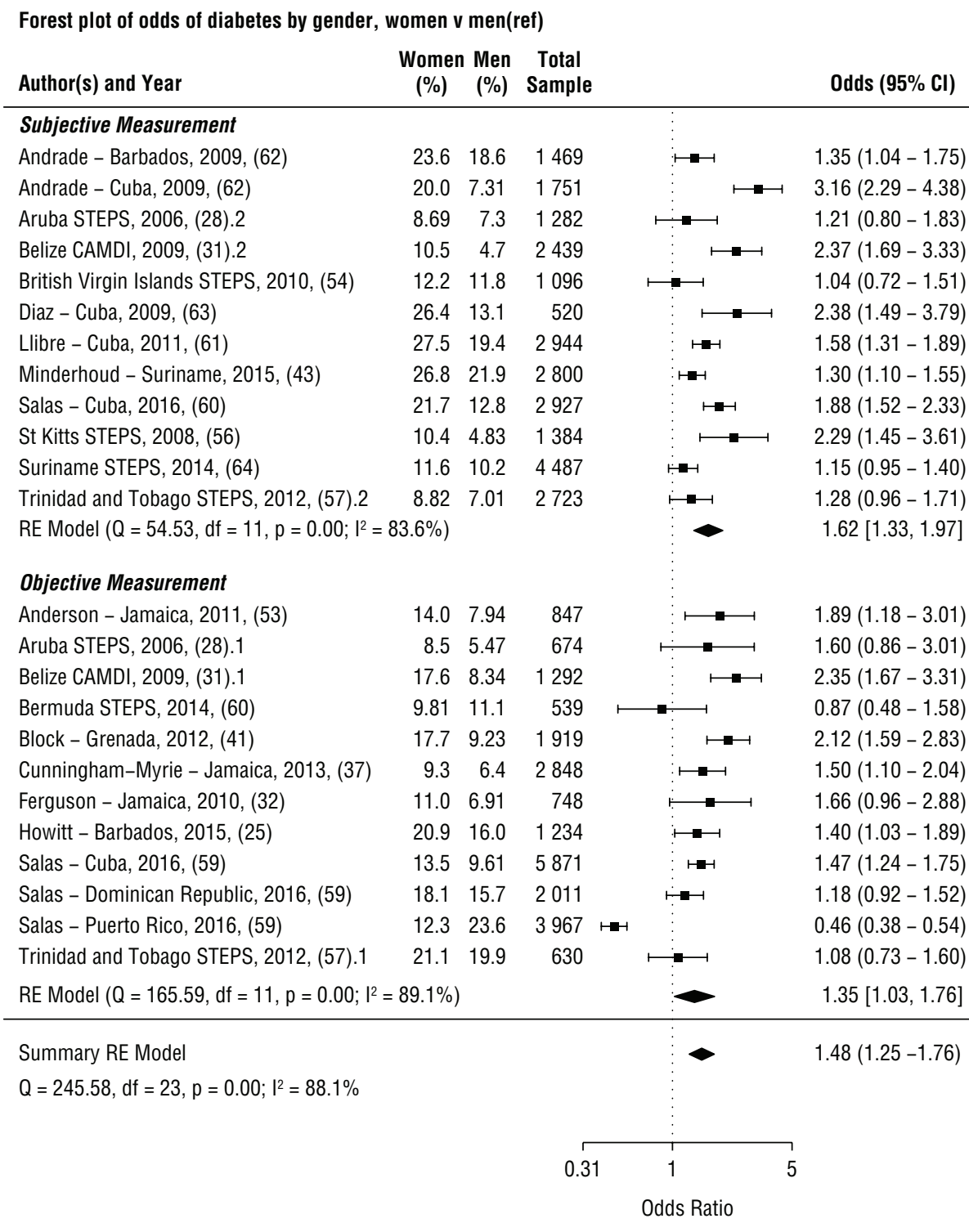

Source: Prepared by the authors using already published, publicly available data including tables and data presented in published papers and available on the PAHO (www.paho.org) and WHO (www.who.int) websites.

In the interest of capturing a wide range of information, the meta-analyses included all sources, regardless of risk of bias. In sensitivity analyses, excluding studies considered high risk did not affect the strength or direction of effect sizes (these data are available upon request from the corresponding author). Most of the studies were population-based, with generally high response rates and a mix of objective and subjective measures.

A major finding that limited the analytic capacity of the data was the heterogeneity of definitions of social determinants among the studies. For example, some authors defined education by the mean years of education, while others categorized according to completion of a particular education level. This variation in definition and categorization limited between-study comparison-excluding potentially worthwhile data from the analysis on the basis of incompatibility. The WHO STEPwise approach is an example of a standardized methodology that collects several social determinants data in a systematic way (e.g., gender, age, marital status, education, and income) across many countries (7). However, typically STEPS surveys are too small to have sufficient statistical power for meaningful sub-group analyses by social determinant, tending instead to provide precise estimates of prevalence for men, women, and age groups combined. The methodology does not provide sufficient statistical power for stratification by other indicators at the country level. Alternatively, existing sources could be pooled to add statistical power and enable regional estimates of other social determinants by outcome. If leading organizations, such as WHO and PAHO, were to promote the use of standardized, operational definitions of social determinant indicators, they could facilitate more robust and comparable research of health inequalities.

Limitations. A major limitation of this review was the poor data quality and study reports. Of the total articles, $60 \%$ were classified as having a high or moderate risk of bias, with a lack of adjustment for age and other confounders being the largest contributing factor(s). Also, a large proportion of articles lacked detailed descriptions of methodology and outcomes, participant selection, measurement, and confounding. Many had missing data. These issues contributed to $>20 \%$ of papers being classified as having an "unclear" risk of bias. Other systematic reviews of non-randomized evidence in the Caribbean have also reported large proportions with a high risk of bias $(14,48)$. This speaks to the quality of reporting in the region and the necessity for establishing and adopting reporting standards to improve output.

Despite the wide scope of this systematic review, heterogeneous definitions of social determinants (especially education levels, income groups, and measures of socioeconomic status) and outcome measures made it impossible to conduct metaanalyses beyond gender. Opportunities are available for more detailed reporting by social determinants in the STEPS surveys where standardized data on education and income have been collected. However, most of these surveys have not published analyses by social determinants beyond gender and the technical capacity for further analysis is often limited. Data sharing has not been a regional priority, further limiting data reuse.

\section{Conclusions}

This systematic review confirms that women are disproportionately affected 
by type 2 diabetes risk factors in the Caribbean. While efforts have been made to move forward with the Port of Spain Declaration to stop the epidemic of noncommunicable disease (5), targeted prevention strategies are still needed. Describing the differences in proportions of risk factors is useful, but understanding the mechanisms explaining this disparity using qualitative analysis of the perceptions of women and men in the Caribbean is vital (49) to developing targeted policy strategies. Governments have recognized the importance of understanding the social determinants of health starting with the WHO Commission on International Diabetes Federation Diabetes Atlas, 7th Ed. Brussels: International Diabetes Federation; 2015.

2. Unwin N, Whiting D, Roglic G. Social determinants of diabetes and challenges of prevention. Lancet Lond Engl. 2010; 375(9733):2204-5.

3. World Health Organization. Closing the gap in a generation: Health equity through action on the social determinants of health. Final report of the Commission on Social Determinants of Health. Geneva: WHO; 2008.

4. Sobers-Grannum N, Murphy MM, Nielsen A, Guell C, Samuels TA, Bishop L, et al. Female gender is a social determinant of diabetes in the Caribbean: a systematic review and meta-analysis. PloS One. 2015;10(5):e0126799.

5. Samuels TA, Guell C, Legetic B, Unwin N. Policy initiatives, culture and the prevention and control of chronic non-communicable diseases (NCDs) in the Caribbean. Ethn Health. 2012;17(6):631-49.

6. Welch V, Petticrew M, Tugwell P, Moher D, O'Neill J, Waters E, et al. PRISMA-Equity 2012 extension: reporting guidelines for systematic reviews with a focus on health equity. PLoS Med. 2012;9(10):e1001333.

7. World Health Organization. STEPS Manual. 2017. Available from: http:// www.who.int/ncds/surveillance/steps/ manual/en/Accessed 18 September 2018.

8. Pan American Health Organization/ World Health Organization Country Reports. Available from: http://www. paho.org/hq/index.php?option $=$ com $_{-}$ content\&view $=$ article\&id $=5006 \% 3$ A2011country-reports\&catid $=1384 \% 3$ Acncdsurveillance \&Itemid $=40597 \&$ lang $=$ en Accessed 10 April 2018.

9. World Health Organization. NCDs । STEPS Country Reports. Available from: http://www.who.int/ncds/surveillance/steps/reports/en/ Accessed 10 April 2018.
Social Determinants in 2005. In 2017, WHO chose the burden of diabetes on women and their right to health care as the theme for World Diabetes Day (50).

The evidence presented here confirms the greater burden borne by women with regards to obesity and physical inactivity, two major risk factors for diabetes and diabetes prevalence. It should help guide policymakers in focusing interventions on physical inactivity, obesity, and diabetes, as well as smokingreduction campaigns. However, if health policy leaders, such as WHO and PAHO, are committed to closing the gaps and disparities associated with the social determinants of disease, a unified,

\section{REFERENCES}

10. Ouzzani M, Hammady H, Fedorowicz Z, Elmagarmid A. Rayyan-a web and mobile app for systematic reviews. Syst Rev. 2016;5(1):210.

11. von Elm E, Altman DG, Egger M, Pocock SJ, Gøtzsche PC, Vandenbroucke JP, et al. The Strengthening the Reporting of Observational Studies in Epidemiology (STROBE) Statement: guidelines for reporting observational studies. Int J Surg Lond Engl. 2014;12(12):1495-9.

12. Higgins J, Green S, editors. Cochrane Handbook for Systematic Reviews of Interventions Versions 5.1.0. The Cochrane Collaboration; 2011.

13. Moher D, Liberati A, Tetzlaff J, Altman DG, Group TP. Preferred Reporting Items for Systematic Reviews and MetaAnalyses: The PRISMA Statement. PLOS Med. 2009;6(7):e1000097.

14. Brown CR, Hambleton IR, Hercules SM, Alvarado M, Unwin N, Murphy MM, et al. Social determinants of breast cancer in the Caribbean: a systematic review. Int J Equity Health. 2017;16(1):60.

15. World Health Organization. Global Recommendations on Physical Activity for Health. Geneva: WHO; 2010.

16. Barrett SC, Huffman FG, Johnson P, Campa A, Magnus M, Ragoobirsingh D. A cross-sectional study of Jamaican adolescents' risk for type 2 diabetes and cardiovascular diseases. BMJ Open. 2013;3(7): e002817.

17. Sinnapah S, Antoine-Jonville S, Hue O. The Association of Body Fat and Leisure Time Physical Activity Called into Question for Asian Indians. Ethn Dis. 2016;26(4):485-92.

18. Krishnadath ISK, Jaddoe VWV, Naharvan Venrooij LM, Toelsie JR. Ethnic differences in prevalence and risk factors for hypertension in the Suriname Health Study: a cross sectional population study. Popul Health Metr. 2016;14:33.

19. Krishnadath ISK, Toelsie JR, Hofman A, Jaddoe VWV. Ethnic disparities in the prevalence of metabolic syndrome and its standardized approach to measurement must be put forth and encouraged for country-level surveillance.

Funding. This paper was funded by a health initiatives development grant sponsored by the DFID/MRC/ Wellcome Trust/ESRC (Reference: MR/ N005384/1).

\section{Conflict of interests: None declared.}

Disclaimer. Authors hold sole responsibility for the views expressed in the manuscript, which may not necessarily reflect the opinion or policy of the RPSP/ $P A J P H$ and/or PAHO. risk factors in the Suriname Health Study: a cross-sectional population study. BMJ Open. 2016;6(12):e013183.

20. Sinnapah S, Antoine-Jonville S, Hue O. Is the leisure-time physical activity of Asian Indian Guadeloupean adolescents different from that of their island counterparts? Ethn Health. 2009;14(3):303-14.

21. Ramsaran C, Maharaj RG. Normal weight obesity among young adults in Trinidad and Tobago: prevalence and associated factors. Int J Adolesc Med Health. 2017;29(2).

22. Barbosa AR, Munaretti DB, Coqueiro RDS, Borgatto AF. Anthropometric indexes of obesity and hypertension in elderly from Cuba and Barbados. J Nutr Health Aging. 2011;15(1):17-21.

23. Nemesure B, Wu S-Y, Hennis A, Leske MC, Barbados Eye Study Group. Prevalence of obesity and associated sexspecific factors in an African-origin population. Ethn Dis. 2007;17(3):508-14.

24. Pérez CM, Sánchez H, Ortiz AP. Prevalence of overweight and obesity and their cardiometabolic comorbidities in Hispanic adults living in Puerto Rico. J Community Health. 2013;38(6). Available from: https://www.ncbi.nlm.nih.gov/ pmc/articles/PMC3823746/ Accessed 26 March 2018

25. Howitt C, Hambleton IR, Rose AMC, Hennis A, Samuels TA, George KS, et al. Social distribution of diabetes, hypertension and related risk factors in Barbados: a cross-sectional study. BMJ Open. 2015; 5(12): 0008869.

26. Serrano M, Torres R, Pérez CM, Palacios C. Social environment factors, diet quality, and body weight in 12-year-old children from four public schools in Puerto Rico. P R Health Sci J. 2014;33(2):80-7.

27. Brathwaite N, Brathwaite A, Taylor M. The socio-economic determinants of obesity in adults in the Bahamas. West Indian Med J. 2011;60(4):434-41.

28. Department of Public Health, Central Bureau of Statistics. STEPS Aruba 2006 
Chronic Disease Risk Factor Surveillance Data Book. Aruba; 2006.

29. Luke A, Bovet $P$, Plange-Rhule J, Forrester TE, Lambert EV, Schoeller DA, et al. A mixed ecologic-cohort comparison of physical activity \& weight among young adults from five populations of African origin. BMC Public Health. 2014;14:397.

30. Benet M, Espinosa A, Morejón A, Diez E, Landrove O, Ordúñez PO. Smoking prevalence in Cienfuegos City, Cuba. MEDICC Rev. 2014;16(3-4):14-7.

31. The Central American Diabetes Initiative. The Central America Diabetes Initiative (CAMDI): Survey of Diabetes, Hypertension and Chronic Disease Risk Factors [Internet]. Belize, San José, San Salvador, Guatemala City, Managua and Tegucigalpa. Washington, D.C.: Pan American Health Organization; 2011. Available from: http://www.paho. org $/$ hq $/$ index.php?gid=16710\&option= com_docman\&task=doc_view Accessed 18 September 2018.

32. Ferguson TS, Francis DK, Tulloch-Reid MK, Younger NOM, McFarlane SR, Wilks RJ. An update on the burden of cardiovascular disease risk factors in Jamaica: findings from the Jamaica Health and Lifestyle Survey 2007-2008. West Indian Med J. 2011;60(4):422-8.

33. Baldew S-SM, Krishnadath IS, Smits CC, Toelsie JR, Vanhees L, Cornelissen V. Selfreported physical activity behavior of a multi-ethnic adult population within the urban and rural setting in Suriname. BMC Public Health. 2015;15:485.

34. Colon-Lopez V, Banerjee G, Gertz AM, Ortiz AP, Calo W, Finney-Rutten LJ, et al. Behavioral correlates of fruit and vegetable intake in Puerto Rico: Results from the health information national trends survey. P R Health Sci J. 2013;32(4):194-9.

35. Colon-Ramos U, Finney Rutten LJ, Moser RP, Colon-Lopez V, Ortiz AP, Yaroch AL. The association between fruit and vegetable intake, knowledge of the recommendations, and health information seeking within adults in the U.S. mainland and in Puerto Rico. J Health Commun. 2015; 20(1):105-11.

36. Tull ES, Taylor J. Assessing the association of nativity and acculturation to fast food restaurant use and its relationship to metabolic risk factors among US blacks with Afro-Caribbean ethnicity. Ethn Dis. 2014;24(4):438-43.

37. Cunningham-Myrie $C$, Younger-Coleman N, Tulloch-Reid M, McFarlane S, Francis $\mathrm{D}$, Ferguson T, et al. Diabetes mellitus in Jamaica: sex differences in burden, risk factors, awareness, treatment and control in a developing country. Trop Med Int Health TM IH. 2013;18(11):1365-78.

38. Chadee D, Seemungal T, Pinto Pereira LM, Chadee M, Maharaj R, Teelucksingh S. Prevalence of self-reported diabetes, hypertension and heart disease in individuals seeking State funding in Trinidad and Tobago, West Indies. J Epidemiol Glob Health. 2013;3(2):95-103.

39. Barceló A, Gregg EW, Pastor-Valero M, Robles SC. Waist circumference, BMI and the prevalence of self-reported diabetes among the elderly of the United States and six cities of Latin America and the Caribbean. Diabetes Res Clin Pract. 2007;78(3):418-27.

40. Fuhrman BJ, Smit E, Crespo CJ, GarciaPalmieri MR. Coffee intake and risk of incident diabetes in Puerto Rican men: results from the Puerto Rico Heart Health Program. Public Health Nutr. 2009;12(6):842-8.

41. Block RC, Dozier AM, Hazel-Fernandez L, Guido JJ, Pearson TA. An epidemiologic transition of cardiovascular disease risk in Carriacou and Petite Martinique, Grenada: the Grenada Heart Project, 2005-2007. Prev Chronic Dis. 2012;9:E90.

42. Apparico N, Clerk N, Henry G, Seale J, Sealy R, Ward S, et al. How well controlled are our type 2 diabetic patients in 2002? An observational study in North and Central Trinidad. Diabetes Res Clin Pract. 2007;75(3):301-5.

43. Minderhoud J, Pawiroredjo JC, MesquitaVoigt A-MTB de, Themen HC, Siban MR, Forster-Pawiroredjo CM, et al. Diabetes and diabetic retinopathy in people aged 50 years and older in the Republic of Suriname. Br J Ophthalmol. 2016;100(6):814-8

44. Hambleton IR, Jeyaseelan S, Howitt C, Sobers-Grannum N, Hennis AJ, Wilks RJ, et al. Cause-of-death disparities in the African diaspora: exploring differences among shared-heritage populations. Am J Public Health. 2015;105 Suppl 3:S491-498.

45. Guariguata L, Whiting DR, Hambleton I, Beagley J, Linnenkamp U, Shaw JE. Global estimates of diabetes prevalence for 2013 and projections for 2035. Diabetes Res Clin Pract. 2014;103(2):137-49.

46. Willi C, Bodenmann P, Ghali WA, Faris $\mathrm{PD}$, Cornuz J. Active smoking and the risk of type 2 diabetes: a systematic review and meta-analysis. JAMA. 2007;298(22): 2654-64.

47. Ng M, Freeman MK, Fleming TD, Robinson M, Dwyer-Lindgren L, Thomson $\mathrm{B}$, et al. Smoking prevalence and cigarette consumption in 187 countries, 1980-2012. JAMA. 2014;311(2):183-92.

48. Brown CR, Hambleton IR, SobersGrannum N, Hercules SM, Unwin N, Nigel Harris E, et al. Social determinants of depression and suicidal behaviour in the Caribbean: a systematic review. BMC Public Health. 2017;17(1):577.

49. Alvarado M, Murphy MM, Guell C. Barriers and facilitators to physical activity amongst overweight and obese women in an Afro-Caribbean population: A qualitative study. Int J Behav Nutr Phys Act. 2015;12:97.

50. World Health Organization. World Diabetes Day 2017. Available from: http:/ / www.who.int/diabetes/world-diabetesday/en/ Accessed 22 December 2017.

51. Atiase Y, Farni K, Plange-Rhule J, Luke A, Bovet $\mathrm{P}$, Forrester TG, et al. A comparison of indices of glucose metabolism in five black populations: data from modeling the epidemiologic transition study (METS). BMC Public Health. 2015;15:895.

52. Soloway LE, Demerath EW, Ochs N, James GD, Little MA, Bindon JR, et al. Blood pressure and lifestyle on Saba, Netherlands Antilles. Am J Hum Biol Off J Hum Biol Counc. 2009;21(3):319-25.
53. Anderson SG, Younger N, Heald AH, Tulloch-Reid MK, Simukonda WP, Mbanya $\mathrm{J}-\mathrm{C}$, et al. Nutrient intakes and dysglycaemia in populations of West African origin. Br J Nutr. 2011;105(2):297-306.

54. Ministry of Health and Social Development British Virgin Islands. British Virgin Islands STEPS Noncommunicable Disease Risk Factors Survey 2009. Road Town: BVI Ministry of Health; 2010.

55. Ministry of Health Cayman Islands. WHO STEPS Chronic Disease Risk Factor Survey 2012 - Cayman Islands. Cayman Islands: Ministry of Health, Environment, Youth, Sports and Culture - Cayman Islands Government; 2012.

56. Ministry of Health St Kitts and Nevis. Saint Kitts and Nevis STEPS Noncommunicable Disease Risk Factors Survey 2008. St Kitts and Nevis: World Health Organization; 2008.

57. Ministry of Health Trinidad and Tobago Panamerican STEPs: Chronic Noncommunicable Disease Risk Factor survey Final Report. Trinidad and Tobago: Ministry of Health, Government of Trinidad and Tobago; 2011.

58. Ministry of Health Grenada. WHO STEPS Chronic Disease Risk Factor Surveillance. Grenada; 2011.

59. Salas A, Acosta D, Ferri CP, Guerra M, Huang Y, Jacob KS, et al. The Prevalence, Correlates, Detection and Control of Diabetes among Older People in Low and Middle Income Countries. A 10/66 Dementia Research Group PopulationBased Survey. PloS One. 2016;11(2):e0149616.

60. Ministry of Health Bermuda. Steps to a well Bermuda 2014 - PAHO-WHO NonCommunicable Disease Risk Factor Survey. Bermuda: Government of Bermuda Ministry of Health, Seniors and Environment; 2014.

61. Llibre J de J, Valhuerdi A, Calvo M, García RM, Guerra M, Laucerique $\mathrm{T}$, et al. Dementia and other chronic diseases in older adults in Havana and Matanzas: the 10/66 study in Cuba. MEDICC Rev. 2011;13(4):30-7.

62. Andrade F. Estimating diabetes and diabetes-free life expectancy in Mexico and seven major cities in Latin America and the Caribbean. Rev Panam Salud Publica. 2009;26(1):9-16.

63. Díaz ME, Jiménez S, García RG, Bonet $M$, Wong I. Overweight, obesity, central adiposity and associated chronic diseases in cuban adults. MEDICC Rev. 2009;11(4):23-8.

64. Ministry of Health Suriname. National Health Survey Suriname. Suriname: Ministry of Health; 2014.

65. Laborde JE, Sáez-Santiago E. Association between obesity and symptoms of depression of adults in Puerto Rico. P R Health Sci J. 2013;32(3):132-7.

66. Rodrigues Barbosa A, Ferreti Borgatto A. Arterial hypertension in the elderly of Bridgetown, Barbados: prevalence and associated factors. J Aging Health. 2010; 22(5):611-30.

67. Tulloch-Reid MK, Younger NO, Ferguson TS, Francis DK, Abdulkadri AO, GordonStrachan GM, et al. Excess Cardiovascular Risk Burden in Jamaican Women Does 
Not Influence Predicted 10-Year CVD Risk Profiles of Jamaica Adults: An Analysis of the 2007/08 Jamaica Health and Lifestyle Survey. PLOS ONE. 2013;8(6):e66625.

68. Ferguson T, Younger N, Tulloch-Reid M, Lawrence-Wright M, Forrester T, Cooper R, et al. Progression from Prehypertension to Hypertension in a Jamaican Cohort: Incident Hypertension and its Predictors. West Indian Med J. 2010;59(5):486-93.

69. Nordet P, Mendis S, Dueñas A, de la Noval

R, Armas N, de la Noval IL, et al. Total cardiovascular risk assessment and management using two prediction tools, with and without blood cholesterol. MEDICC Rev. 2013;15(4):36-40.

Manuscript received on 11 April 2018. Accepted for publication on 15 August 2018.
RESUMEN

Revisión sistemática y metanálisis actualizados sobre los determinantes sociales de la diabetes y los factores de riesgo conexos en el Caribe

Palabras clave
Objetivos. Analizar los datos más recientes sobre la diabetes y sus factores de riesgo desglosados por género y otros determinantes sociales de la salud para comprender por qué su prevalencia en el Caribe es mayor en las mujeres que en los hombres, fundamentar la definición de la agenda de políticas para la prevención y el control de la diabetes en el Caribe, y determinar las brechas en la evidencia que requieren mayor investigación.

Métodos. Se actualizó una revisión sistemática anterior de la bibliografía que describe los estudios realizados en el Caribe acerca de la distribución de la diabetes, sus resultados y sus factores de riesgo por uno o varios determinantes sociales, con el objetivo de incluir otras fuentes publicadas en el periodo comprendido entre el 1 de enero del 2007 y el 31 de diciembre del 2016, además de encuestas realizadas por la Organización Mundial de la Salud (OMS). En los casos en los que se contaba con datos suficientes, se emprendieron metanálisis.

Resultados. Se encontró un total de 8.326 artículos, entre los que se seleccionaron 282 para llevar a cabo un examen del texto íntegro y 114 para realizar un resumen. En conjunto, 36 artículos, entre los que se incluyen las encuestas relacionadas con la OMS, disponían de la información suficiente para su metanálisis. En comparación con los hombres, un mayor número de mujeres eran obesas (razón de posibilidades [OR]: 2,1; IC de $95 \%=1,65-2,69$ ), físicamente inactivas (OR: 2,18; IC de 95\% = 1,75-2,72) y tenían diabetes (OR: 1,48; IC de 95\% =1,25-1,76). Un mayor número de hombres eran fumadores (OR: 4,27; IC de $95 \%=3,18-5,74$ ) y presentaban un consumo insuficiente de frutas y verduras (OR: =1,37; IC de $95 \%=1,21-1,57)$.

Conclusiones. Se agregaron 36 artículos a la revisión sistemática realizada con anterioridad y, de ellos, se añadieron 13 al metanálisis. La diabetes y sus factores de riesgo (fundamentalmente, la obesidad y la inactividad física) siguen afectando desproporcionadamente a las mujeres en el Caribe. En esta zona geográfica, las intervenciones contra el tabaquismo deben dirigirse a los hombres.

Diabetes mellitus; enfermedades no transmisibles; género y salud; obesidad; factores de riesgo; Región del Caribe. 
RESUMO

Revisão sistemática e meta-análise atualizadas dos determinantes sociais da diabetes e fatores de risco relacionados no Caribe

Palavras-chave
Objetivos. Examinar os dados mais recentes sobre diabetes e fatores de risco relacionados por gênero e outros determinantes sociais da saúde para entender por que a prevalência da doença é maior no sexo feminino que no masculino no Caribe; obter subsídios para estabelecer a agenda de políticas para prevenção e controle da diabetes no Caribe; e identificar as lacunas nas evidências que precisam de uma investigação mais aprofundada.

Métodos. Uma revisão sistemática anterior da literatura de estudos realizados no Caribe que apresentavam dados da distribuição da diabetes, desfechos e fatores de risco relacionados a esta doença, por um ou mais determinantes sociais, foi atualizada com a inclusão de novas fontes de informação para o período de $1^{\circ}$ de janeiro de 2007 a 31 de dezembro de 2016. Foram incluídas também pesquisas feitas pela Organização Mundial da Saúde (OMS). Meta-análises foram conduzidas quando havia dados suficientes.

Resultados. Ao todo, 8.326 manuscritos foram identificados. Destes, 282 foram selecionados para leitura completa de texto e 114 foram separados para a coleta de dados. Trinta e seis artigos, incluindo as pesquisas da OMS, continham dados suficientes para uma meta-análise. Verificou-se uma proporção maior de mulheres em comparação aos homens com obesidade (OR 2,1; IC95\% 1,65-2,69), inatividade física (OR 2,18; IC95\% 1,75-2,72) e diabetes (OR 1,48; IC95\% 1,25-1,76). Observou-se também que uma proporção maior de homens era fumante (OR 4,27; IC95\% 3,18-5,74) e tinha consumo inadequado de frutas e verduras (OR 1,37; IC95\% 1,21-1,57).

Conclusões. Foram acrescentados 36 artigos à revisão sistemática anteriormente realizada. Destes, 13 foram incluídos na meta-análise. A diabetes e fatores de risco relacionados (sobretudo obesidade e inatividade física) continuam afetando de forma desproporcional as mulheres no Caribe. Intervenções para combater o tabagismo devem ser dirigidas ao sexo masculino nesta região geográfica.

Diabetes mellitus; doenças não transmissíveis; gênero e saúde; obesidade; fatores de risco; Região do Caribe. 